This item was submitted to Loughborough's Research Repository by the author.

Items in Figshare are protected by copyright, with all rights reserved, unless otherwise indicated.

\title{
Unveiling hidden knowledge: discovering the hygiene needs of perimenopausal women
}

\section{PLEASE CITE THE PUBLISHED VERSION}

https://doi.org/10.3828/idpr.2018.34

\section{PUBLISHER}

Liverpool University Press

VERSION

AM (Accepted Manuscript)

\section{PUBLISHER STATEMENT}

This work is made available according to the conditions of the Creative Commons Attribution-NonCommercialNoDerivatives 4.0 International (CC BY-NC-ND 4.0) licence. Full details of this licence are available at: https://creativecommons.org/licenses/by-nc-nd/4.0/

\section{LICENCE}

CC BY-NC-ND 4.0

\section{REPOSITORY RECORD}

Bhakta, Amita, Julie Fisher, and Brian Reed. 2019. "Unveiling Hidden Knowledge: Discovering the Hygiene Needs of Perimenopausal Women”. figshare. https://hdl.handle.net/2134/36388. 


\title{
Unveiling hidden knowledge: discovering the hygiene needs of perimenopausal women
}

\begin{abstract}
The provision of adequate water, sanitation and hygiene (WASH) services to ensure good health and wellbeing for all is incorporated into the Sustainable Development Goals, with the aim to 'leave no-one behind'. The WASH needs of perimenopausal (PM) women are largely absent from academic literature. These personal needs are hidden knowledge. However, this article demonstrates the use of participative methodologies to 'unveil' these. A UK-based phenomenological review set the research agenda using PM women's narratives; this was later developed in urban Ghana using oral history interviews, participatory mapping and PhotoVoice. Allowing for some adaption of these tools to account for local taboos in the global South, issues were revealed that are invisible to many but still warrant attention. Moving beyond theoretical discourse, practical approaches identified infrastructural issues and ensured the inclusion of PM experience. Unveiling hidden knowledge in this way has wider implications for other issues in development agendas.
\end{abstract}

Keywords: hidden knowledge, WASH, menopause, menstruation, hygiene, sanitation

\section{Introduction}

Some aspects of individuals' lives are hidden from other people, such as sexuality, bathing during menstruation for women and girls, or health issues with no visible symptoms, such as mental health. This paper uses one hidden aspect of women's lives - meeting water, sanitation and hygiene (WASH) needs during the perimenopause - as a vehicle to explore how hidden knowledge about issues such as these can be found using appropriate methodologies. This article is about the methodological results of how to find hidden knowledge, demonstrating this by using reflections from research on the WASH needs of perimenopausal women. The focus of the article is on the methodology of finding hidden knowledge rather than the findings of the WASH needs of perimenopausal women. Women going through the perimenopause - the reproductive transition phase to menopause - have specific hygiene needs, such as bathing, menstrual hygiene management (MHM) and laundry. In a low-income country, where basic water and sanitation services are often lacking, these needs can be difficult to fulfil. The provision of adequate WASH has been highlighted as key to the Sustainable Development Goals (SDGs) adopted in 20I5; target 6. I is to 'by 2030, achieve universal and equitable access 
to safe and affordable drinking water for all', and target 6.2 is to 'achieve access to adequate and equitable sanitation and hygiene for all and end open defecation, paying special attention to the needs of women and girls and those in vulnerable situations' (UN, 20I6). Of the 663 million people without access to improved drinking water supply, and the 2.4 billion people without improved sanitation (UNICEF and WHO, 20I5), an estimated 3.6 per cent of these are perimenopausal (PM) women aged between fortyfive to fifty-four years (UN, 2015[AQ2]), with perimenopause beginning on average from ages forty-seven to fifty-one years over a period of four years (Loue and Sajatovic, 2008). To meet the SDGs, hidden knowledge such as WASH during the perimenopause, which is not easily discussed by women and is absent from the literature, requires greater exploration in the context of this ageing population, particularly in the global South. This research on the WASH needs of PM women had four objectives: I) to determine the hygiene management needs of PM women; 2) to determine PM WASH needs; 3) to assess how human, social, natural, physical and financial factors influence PM WASH experiences; and 4) to identify appropriate measures to meet and address PM WASH needs.

The main SDG relating to $\mathrm{PM}_{\text {women is }} \mathrm{SDG}_{5}$, to 'achieve gender equality and empower all women and girls', with the target to 'ensure universal access to sexual and reproductive health' (UN, 2016 [AQ3]). However, wider discussions on women's reproductive health have tended to focus on aspects of sexual health and birth control rather than the menopause. WASH research has a growing body of work on MHM for adolescent girls) (Jewitt and Ryley, 20I4; Crofts and Fisher, 20I2). However, MHM for PM women, with different needs to younger women, is ignored.

We discuss here how a lack of public or shared knowledge about PM women's WASH needs in the literature (Bhakta et al., 20I4) led to the initial stages of this research being conducted in the UK. We then discuss how this was used to establish a research framework and to develop effective methods to access similar knowledge in a low-income country context. These methods were subsequently tested and refined in communities in Accra and Kumasi in Ghana, where WASH service provision is inadequate.

\section{A case study of hidden knowledge: the WASH needs of PM women}

'Hidden knowledge' is that which is known by an individual or specific group, but has no written record, and is not shared with others. There are three dimensions of the 'hiddenness' of PM WASH needs: academic neglect through a lack of research and literature on the topic; the social taboo preventing discussion on WASH among women or between women and others (particularly men); and the physical privacy in which PM WASH practices are performed. 


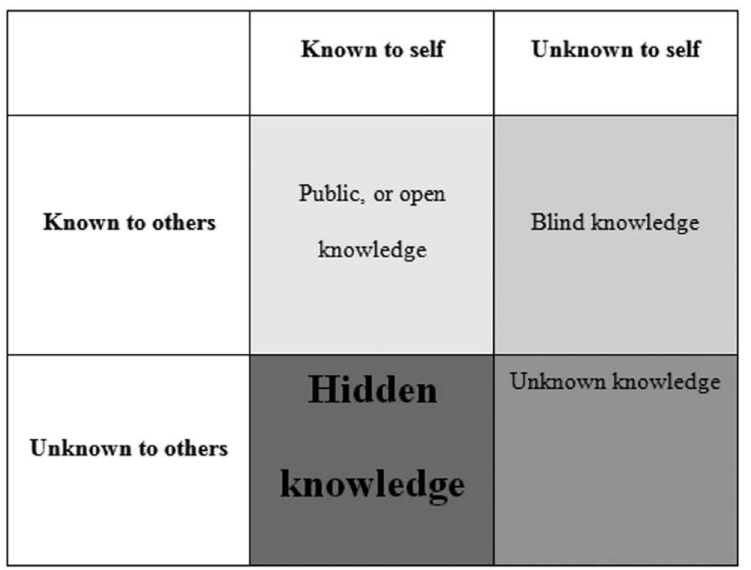

Figure 1 The Johari Window Source: [AQ16]

The Johari Window, represented within a two-by-two matrix (Figure I), is useful to understand forms of knowledge held by an individual (Shenton, 2007 [AQ4]).

The four panes of the Johari Window denote public, blind, hidden, and unknown knowledge (Luft, I96I), and can be used to situate PM WASH needs:

I) Public or open knowledge is known to self and to others. PM WASH needs are not public knowledge, not widely known to external actors, who are not PM or menopausal women.

2) Blind knowledge is self-unawareness of aspects within ourselves that others can see. PM WASH needs are not blind knowledge, because women are aware although they cannot be seen by others.

3) Hidden knowledge is known by individuals but not revealed to others. PM WASH needs are hidden knowledge, because PM and menopausal women are aware, but others are not.

4) Unknown knowledge is not known by individuals or others. PM WASH needs are known by PM and menopausal women, and therefore not unknown.

PM WASH needs are hidden knowledge held by all PM or menopausal women with experience of this biological transition. However, PM women can experience this in isolation, in a 'bubble' on their own. Furthermore, PM changes and symptoms are less publicly visible than those during puberty.

The analogy of an onion is useful here, with PM WASH needs at its core, with each layer providing an element of 'hiddenness'. The innermost layer is neglect by mainstream science. The outer layers are social and academic. These include the taboos surrounding the perimenopause, and its neglect by WASH practitioners and academics alike. Intersectionality of other identities leaves the perimenopause buried under other issues, for example, PM women are hidden in an ageing population. Each of these layers requires peeling back to see the issues at the core of the onion. Researchers therefore need to first acknowledge that PM WASH is a topic of importance. 


\section{Hidden issues}

The WASH sector seeks to ensure that provision is inclusive for all. Inclusion ensures that all individuals, including the disadvantaged, discriminated against and marginalised, have access to services, and an active engagement in wider processes relating to these rights (Gosling, 20I0). Hidden issues can be assessed through the lens of structural intersectionality, which is ' $[\mathrm{t}]$ he material consequences of the interaction of [... multiple hierarchies [in lives]' (Crenshaw, I997, 552). Crenshaw (I997) argues for the use of this to enable individuals' subjective experiences to be made more visible, through making salient social structures that play a role in exclusion and hiddenness more vivid (Carastathis, 20I4). This approach demonstrates how exclusion manifests through hegemonic, structural, interpersonal and disciplinary structures and is maintained through different aspects of an individual's identity (Dill and Zambrana, 2009).

Identifying individuals using single categories of identity therefore comes under scrutiny (Carastathis, 20I4). Whilst gender and ageing are visible on the 'outside', issues such as menstruation are not. Hidden issues such as PM WASH can therefore be studied through an intracategorical lens that examines complexities within a group (McCall, 2005), because these issues are commonly ignored when studying women, who can themselves be an excluded group.

Exploring methodologies to achieve this, we respond to Valentine's (2007, I8) call to develop 'a new body of empirically grounded research into the lived experience of intersectionality rather than relying on theorisation alone to develop this concept'. Intersectionality has relevance to studying women, as Butler $($ I990, 3) [AQ4] argues, 'it becomes impossible to separate out "gender" from the political and cultural intersections in which it is inevitably produced and maintained', because there are different aspects of identity to consider other than being a woman. Feminism in the USA did not arise from the most oppressed women; white middle-class women and their privileged experiences dominate its theorisation (hooks, I984).

Discussions on hard-to-reach groups focus on individuals who are physically or socially hidden, and who avoid contact with officials such as census enumerators (Singer, 2013). Others are hidden by their circumstances, such as drug users (Elliot et al., 2002) and prostitutes (Faugier and Sargeant, I997). Groups dealing with multiple issues are hidden, for example LGBTQ who are facing domestic violence in the workplace (Harek, 2009 [AQ4]). Participants can be less willing to engage with research, particularly on sensitive issues (Faugier and Sargeant, I997), or which could involve risk (Ellard-Gray et al., 2015).

Hidden groups and hidden issues are different. Hidden groups are fixed and their identity remains constant, e.g. those with disability (Imrie and Edwards, 2007). Hidden issues are found within hidden as well as visible groups and are harder to identify. Issues can be transient, context-specific (gender or socio-economic status), and spatial, 
as they relate to particular spaces but are hidden from others. PM WASH needs is a transient, hidden issue for women from all groups, including other hidden groups. We examine next how appropriate methodologies can help overcome these barriers.

\section{Finding hidden knowledge stage one: literature review}

Approach to the review: literature search and results

A lack of literature on the PM WASH needs strongly suggests that these needs are hidden knowledge. A literature search was conducted between October 2013 and March 20I4 using fifty-nine pre-set search term combinations, using terms including but not limited to: 'perimenopause', 'menopause', 'menstruation', 'water and sanitation' and 'older women', then repeated in 2014, 2015, 2016 and 20I7. The search included PM-related terms such as 'menopause' and 'menstruation'. Two types of databases were searched using the pre-set search term combinations: firstly, specialist WASH collections and non-WASH specific databases, secondly, other sources such as Google Scholar. Different search term combinations were used across databases, including specialist WASH collections (the WEDC Knowledge Base, IRC WASH), Water Resources Abstracts, Science Direct, Geobase and Compendex, Zetoc, Web of Knowledge, ProQuest, Medline and Google Scholar. Searches of the specialist WASH collections excluded WASH-related terms such as 'water supply' and 'sanitation' as they are built into the database. Search term combinations included at least one term relating to the topics of PM (e.g. menopause) and WASH (e.g. sanitation) for each search. Specific inclusion criteria determined relevance of literature to the study: i.e. non-medical, focus on WASH-related practices during perimenopause/ menopause, and relating to the global South. This search was not limited by date to maximise the potential of finding suitable literature.

A PRISMA (Preferred Reporting Items for Systematic Reviews and MetaAnalyses) diagram (Figure 2) shows how the literature retrieved from the databases were synthesised for the literature review:

The first stage of the literature search identified records to be reviewed. Records retrieved from the databases, which were duplicated in different databases, were reviewed by title only, for in-depth screening. Screening involved reading the abstracts of 228 articles with potential relevance to the study, based on the inclusion criteria for the search. 209 abstracts were disregarded at the screening stage. These abstracts discussed topics which did not relate to WASH for PM women. WASH-related literature was found on MHM for adolescent girls, but not for women during the perimenopause. Literature on the menopause was found for different low-income countries, but did not look at WASH, and topics were too far removed from the research. Some results were duplicates (e.g. Chompootweep et al., I993 (7 duplicates); Wasti et al., I993 


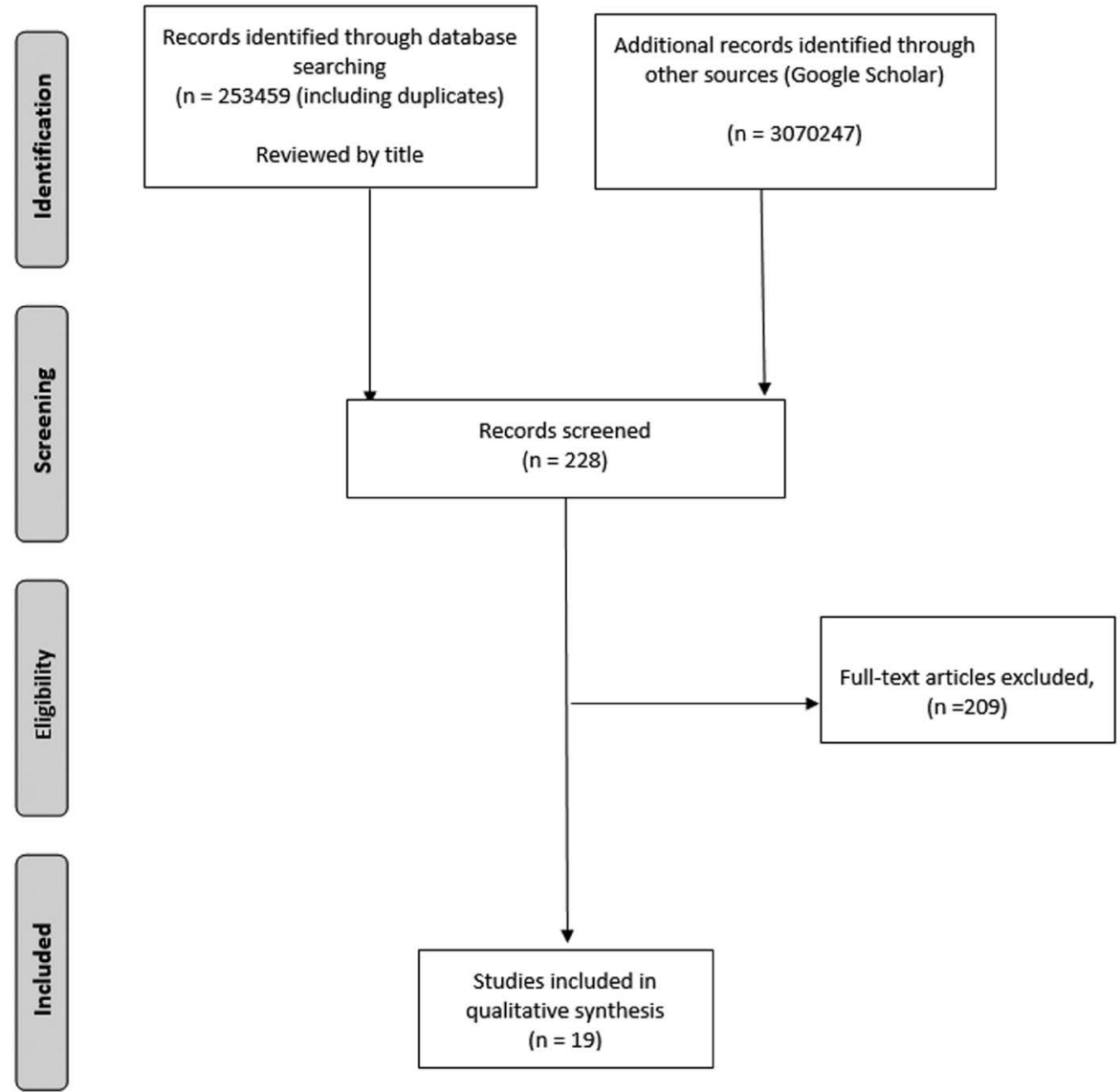

Figure 2 PRISMA diagram of literature search

Source: [AQ16]

(3 duplicates); Castelo-Branco et al., 2005 (4 duplicates)) and appeared in different searches and in different databases. 3, 323, 706 [AQ5] results from all databases collectively were excluded based on titles and the abstracts were not screened because the topics of the papers were entirely unrelated, e.g. amnesia in rats, soybean germplasms or Alzheimer's in monkeys. These results did not relate to and did not mention either perimenopause, or WASH, and were therefore excluded.

Despite annually repeating the search from 2015 to 2017 , no evidence of a link between PM women and WASH was found. Nineteen eligible search results were included in the literature review. Tables I and 2 provide sample results from specialist WASH collections, and Tables 3 and 4 provides sample results from conventional databases: 
Table 1 Sample results of literature search from specialist WASH collection: WEDC Knowledge Base

\section{WEDC Knowledge Base}

\begin{tabular}{lcc} 
Search terms & Results reviewed & Results retrieved \\
\hline Menstrual hygiene management & 25 & 25 \\
Perimenopause AND change of life AND sanitation & 4,829 & 0 \\
Ageing AND bleeding AND menstruation & 12,236 & 0 \\
Ageing AND perimenopause & 15,396 & 0 \\
Total for PM and WASH & 32,461 & 0 \\
\hline
\end{tabular}

Table 2 Sample results of literature search from specialist WASH collection: IRC WASH

\begin{tabular}{lcc}
\hline IRC WASH & Results reviewed & Results retrieved \\
Search terms & 5,526 & 34 \\
\hline Menstrual hygiene management & 0 & 0 \\
Perimenopause AND change of life AND sanitation & 23 & 0 \\
Ageing AND bleeding AND menstruation & 927 & 0 \\
Ageing AND perimenopause & 950 & 0 \\
Total for PM and WASH & & \\
\hline
\end{tabular}

Table 3 Sample results of literature search of non-WASH specific databases: Science Direct

\begin{tabular}{lcc}
\hline Science direct & Results reviewed & Results retrieved \\
Search terms & 1,817 & 12 \\
\hline Menstrual hygiene management & 9 & 0 \\
Perimenopause AND change of life AND sanitation & 18 & 0 \\
$\begin{array}{l}\text { Ageing AND bleeding AND menstruation AND } \\
\text { menstruation AND developing countries }\end{array}$ & 31 & 2 \\
$\begin{array}{l}\text { Ageing AND perimenopause AND developing } \\
\text { countries AND water supply }\end{array}$ & 58 & 2 \\
Total for PM and WASH & & \\
\hline
\end{tabular}

Table 4 Sample results of literature search of non-WASH specific databases: Zetoc

\begin{tabular}{lcc}
\hline Zetoc & Results reviewed & Results retrieved \\
Search terms & 22 & 18 \\
\hline Menstrual hygiene management & 0 & 0 \\
Perimenopause AND change of life AND sanitation & 0 & 0 \\
Ageing AND bleeding AND menstruation AND & & 0 \\
menstruation AND developing countries & 0 & 0 \\
Ageing AND perimenopause AND developing & & 0 \\
countries AND water supply & 0 & \\
Total for PM and WASH & & \\
\hline
\end{tabular}


The search provided literature on MHM for adolescent girls, but not for PM women. Literature also relates to PM women in low-income countries (from a non-WASH perspective), e.g. Pakistan (Wasti et al., I993) and Cameroon (Wambua, I997). Few literature sources indicate possible PM WASH such as effective MHM for menorrhagia (Duckitt, 20I0) and toilet provision for urinary incontinence (Sampselle et al., 2002). Clearly, the link between the perimenopause and WASH is not known from the literature, making a conventional literature review or narrative review unfeasible, because the aim of a narrative review to connect the known to the research topic (Bryman, 2016) could not be fulfilled. An alternative source of information was therefore sought, and effective methodologies were needed to review this hidden knowledge.

\section{Results of the literature review}

\section{Medical understandings of the perimenopause}

The perimenopause is marked by changing hormones, particularly a decline in oestrogen production (Taffe and Dennerstein, 2002[AQ4]). Women experience wideranging PM symptoms because of declining oestrogen. PM symptoms include: night sweats, shorter menstrual cycles (Prior 2005), irregular periods (Harlow et al., 2006), menorrhagia or heavy and prolonged menstrual bleeding (Duckitt, 20Io), joint pain (Briggs and Kovacs, 2015), hot flushes (Stearns et al, 2002), urinary incontinence (Sampselle et al., 2002), dizziness, (Nachtigall, I998) and dry skin (Avis et al., 2009).

\section{The perimenopause in the global South}

In Africa, the average age of the menopause is 48 (Okonofua et al., I990). In Zimbabwe, PM women from the Mashona racial group experienced sweats, hot flushes, palpitations, urinary problems, joint pains, backache, headache, pain during intercourse and changes to hair and skin (Moore, I98I). Egyptian women experience more climacteric symptoms than women in high-income countries (Gadalla, I986), including high prevalence of hot flushes, eight tiredness, [AQ6] vaginal dryness, and ageing-related problems with backache (Gohar, 2005). Hammam et al. (2012) found that working Egyptian women reported exacerbation of menopausal symptoms in the absence of sanitary facilities. In Ghana, the average menopausal age is 48.05 years (Kwawukume et al., I993). Symptoms experienced by menopausal women in Ghana include irregular periods, hot flushes, night sweats, incontinence, tiredness, palpitations, headaches, joint pain, sleep loss, vaginal dryness, decreased coitus, poor memory and weight gain (Kwawukume et al., I993; Seffah et al., 20o8; Odiari and Chambers, 2012; Sertorglo et al., 2012). The menopausal rating scale used in Europe and America is valid for Nigerian women (Kupoluyi et al., 2015).

Urban slum dwellers in Karachi, Pakistan, are less likely to experience PM 
symptoms (Wasti et al., I993). Low socio-economic status and the attendant problems of their situation leads to women overlooking these symptoms. Lower bone mineral density among Pakistani menopausal women causes higher levels of osteoporosis (Akhalaque et al., 2017). In Gujarat, India (Trivedi and Pandya, 20I7), menopausal women experience hot flushes, night sweats, joint pain, mood swings, forgetfulness, loss of libido, sleep loss, cardiovascular disease and weight gain. In Thailand, PM women experience hot flushes, night sweats, insomnia, shortness of breath, urinary problems and an upset stomach (Chompootweep et al., I993; Punyahotra et al., 1997). Chinese nurses reported that hot flushes and sweats increase during PM (Liu et al., 2013). A menopausal age of forty-five in Vietnam poses the highest risk of getting type 2 diabetes compared to women who were menopausal at a later age (Binh and Nhung, 2016). Hamid et al. (2015) discuss menopausal urinary incontinence in Iran, identifying possible needs for more laundry and bathing to deal with urinary incontinence, one of the very sparse links to WASH found in the literature.

Women in the Brazilian Western Amazon report hot flushes, muscular-skeletal joint pain, and worries over ageing (da Silva and d'andretta Tanaka, 2013). Perimenopausal Movima Bolivian women had genital itching and hot flushes (Castelo-Branco et al., 2005).

Summary of the findings of the literature review

The literature review identified medical literature on PM symptoms in the global South, but not on WASH needs; therefore the literature gap on PM WASH remained significant. The literature review did not facilitate the setting of research aims and objectives, because the literature gap was too wide. Finding this hidden knowledge needed participative techniques, grounded in feminist approaches. Enabling PM women to raise their WASH needs was critical to the academic process because the literature review had failed.

\section{Finding hidden knowledge stage two: research design, feminist methodologies and putting perimenopausal women at the centre}

Women's hidden voices: the need for feminist research

Harding $(1987,3)$ affirms that 'traditional theories have been applied in ways that make it difficult to understand women's participation in social life'. Predominantly male discourses in traditional research methods, ways of knowing and writing have silenced women's experiences (Brisolara, 20I4). Feminist research methodologies can access unvoiced and hidden experiences. The silencing of women's voices, 
which therefore become hidden, provides the rationale for feminist research, to be with women rather than on women. 'Feminist research is about the development and construction of knowledge founded on the relationship between women's everyday experience, academic knowledge, political power and social action' (O'Neill, I996, I3I). As such, women are active participants in research, socially constructing empowerment, knowledge and social change.

Feminist research has two traditional epistemologies: feminist empiricism and feminist standpoint. Feminist empiricism argues that good science warrants good empirical methodologies. The focus is the exclusion of women as researchers and participants, and the resulting negative effects of this on women (Harding, I986). The feminist standpoint epistemology has two theses. Firstly, 'situated knowledge' makes the claim that experiences and knowledge are influenced by social location, (being a woman), therefore, knowledge is derived from a particular standpoint. Secondly, an epistemic advantage lies within the standpoints of marginalised or oppressed groups (Wylie, 2003). Our research draws on the individual and subjective WASH needs of PM women, whose voices are unheard. A feminist constructivist approach to understanding knowledge, which is based on individual experience, was best suited to the research.

This discourse leads to using a participatory methodology, essential to reveal hidden, tacit PM WASH needs by placing them at the centre of the research, voicing their own realities and what matters to them (Sangster, I994). Perimenopausal women are 'internal' stakeholders who narrate their realities, whilst the 'external' stakeholder, (e.g. the feminist researcher) evaluates these events without any influence from traditional perspectives (Woodfield, I997). Effective methodologies, suitably adapted, are needed to unveil hidden PM WASH needs.

\section{Women's hidden issues: the perimenopause}

In the global North, when women go through 'the change' - the commonly used term referring to perimenopause - the irrevocability of the menopause and the end of the reproductive years is marked without any public rite of passage (Greer, I99I) or obvious external physical change. Changes for pubescent girls are more physically recognisable and discussed between peers. However, it can be difficult for a menopausal woman to talk to other women about her experiences, facing them secretively (Greer, I99I). The menopause is conducted privately, unless medical intervention is needed, and therefore is silenced (Sheehy, I994[AQj]). Menopause is ignored in wider society; women seldom know much about the menopause until they reach it, with only a possibility that women will discuss it after this point (DeLeyser and Shaw, 20I3). In the global South, issues associated with menstruation and menopause are not discussed in public, due to social attitudes. Taboos relating to perimenopause restrict 
women's activities, such as cooking, with women unable to discuss their experiences (Bhakta et al., 20i6).

Putting the first last: placing perimenopausal women at the centre

Meeting hygiene needs for PM women requires appropriately engineered physical infrastructure, therefore engineering and development discourses were used for research design. Participatory Rural Appraisal [AQ8] argues for transfers of power from dominant 'uppers', to subordinate, weak 'lowers'. 'Whose reality matters' when designing infrastructure for people warrants consideration (Chambers, I997). Those with power can sit and listen to those without power and are 'last'. Researchers must also put the first, last.

The methodology used in this research transfers power from male-dominated local and national government, responsible for policy making, to listen to and put PM women at the centre of the study. They are prone to overlapping dimensions of exclusion: being older women, taboos about perimenopause, the importance of unseen, private spaces such as toilets and bathrooms, and living in low-income communities in the global South, with inadequate water and sanitation access. Finding hidden knowledge requires PM women to self-identify and come forward to be listened to.

\section{Results: unveiling hidden knowledge}

The results of this article are methodological [AQ9]. The purpose of the results section is to demonstrate the methods that can be used to unveil hidden knowledge. The results are about the effectiveness of these methods, showing their use in researching the WASH needs of perimenopausal women as a case study. A summary of the findings, which prove that these methods are effective, is provided later in this paper. The methodological results [AQ9] show the methods adopted and their outcomes to find hidden knowledge.

Data collection took place with women in the UK (phase one) and Ghana (phase two). All participants were either perimenopausal and could reflect on their current experiences, or menopausal and could reflect retrospectively. In phase one, twentythree women, aged from early thirties to late seventies, participated in semi-structured interviews. Women who were either working, looking for work, or retired, were recruited from churches, women's organisations and academic institutions in urban areas of the UK. Women of diverse ethnic backgrounds provided a range of experiences of PM WASH, raising potential issues for Ghanaian women. All women in the UK had full access to improved water supply and sanitation.

Data collection phase two was conducted in the low-income urban communities of La, (in the La Dade-Kotopon Municipal Authority (LaDMA) area) Accra and 
Kotei, (in the sub-metro of Oforikrom) Kumasi, Ghana. In contrast to the UK, La and Kotei have poor water supply and sanitation services and infrastructure. 44 per cent of LaDMA residents (Ghana Statistical Service, 2014) and 47 per cent of Kotei residents (Leathes, 2012) use public toilet facilities. 32 per cent of LaDMA residents receive piped drinking water inside the dwelling (Ghana Statistical Service, 20I4) and 86 per cent of Kotei residents purchase water from boreholes, hand-dug wells and on-sellers (Leathes, 2012). Women, aged from their mid-forties to late seventies, were mostly unemployed and looking for work, retired or engaged in marginal work such as petty trading. Participants from La were of Ga ethnicity, whilst women in Kotei were of Twi ethnic background. Women participated in semi-structured interviews, participatory mapping and participatory photography.

\section{Data collection phase one: UK}

\section{Letting PM women set the agenda}

Phase one used a phenomenological review as an alternative to a literature review. A phenomenological review aims to 'arrive at the essence of researchers' empirical experiences with a phenomenon' with a research report acting as the unit of analysis (Randolph, 2009, IO). A phenomenological review was needed as a stage of finding hidden knowledge of PM WASH needs, because the conventional literature review failed to reveal the WASH needs warranting investigation. In keeping with the feminist stance taken, a qualitative approach was used. Feminist methodologies use semi-structured interviews to emphasise women's perspectives through a two-way non-hierarchal conversation, which builds rapport and facilitates reciprocity (Oakley, I98I). The semistructured interviews took a feminist oral history approach. Oral history $(\mathrm{OH})$ is 'the act of recording the speech of people with something interesting to say then analysing their memories of the past' (Abrams, 20I0, I [AQ4]). Feminist OH captures women's voices that are ignored by traditional historical sources. This challenges mainstream scientific approaches that focus on objective knowledge, and reduce socio-individual interactions to mechanistic behaviours which can only be used to describe rather than to explain findings (Grosz, 1987). OH is an effective means to validate the lives of women, and to contest wider political, social and economic discourses which obscure them (Sangster, 1994). Oral historians call for a 'shared authority' between researcher and researched, and the collaborative creation of a narrative (Shopes, 2003). The cooperative interview reduces distance (Oakley, I98I) and creates trust between the participant and the researcher. Through an $\mathrm{OH}$ approach, participants 'do not speak in the abstract, but speak to the researcher, with the researcher, and inasmuch as the material is published, through the researcher' (Portelli, 1998, 72).

In researching PM WASH needs, $\mathrm{OH}$ techniques align with the community participation ladder (Figure 3), which changes perspectives from viewing communi- 


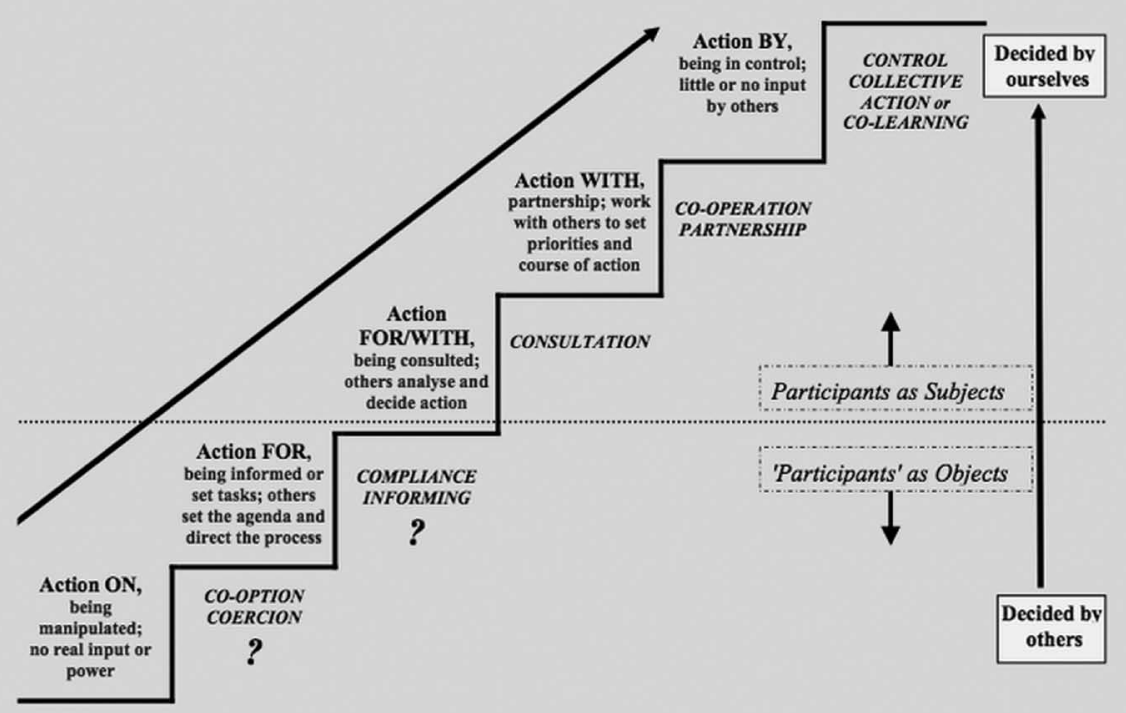

Figure 3 The community participation ladder Source: DFID, 2003

ties as objects of study to engaged participants. It considers implications of research methods for sharing decision-making power. Citizens are engaged in the lower rungs but those with power make decisions for them. In the higher levels, participants are part of the decision-making process and can act with little input from external stakeholders (DFID, 2003). Finding hidden knowledge on PM WASH needs through the phenomenological review enabled women to climb the ladder from the bottom and set the research objectives according to what matters to them.

The phenomenological review results, at the bottom of the participation ladder, identified issues to explore which are unrecorded in the literature. Women's narratives focus on day-to-day MHM practices in managing their symptoms in relation to WASH, such as increased water use for laundry and frequent bathing during menorrhagia, hot flushes, sweating, urinary incontinence, joint pains and dry skin. These experiences are dealt with privately.

Due to the failure of the literature review in identifying WASH needs to explore in the research, the phenomenological review findings were needed to set the research objectives for the study, as outlined earlier in the article. Details of WASH needs and practices assisted in establishing specific research questions, for instance, 'what are the issues faced in (physical, social and financial) access to water after day/night sweats and hot flushes?' The phenomenological review thus identified daily, hidden WASH practices to deal with PM symptoms, (e.g. bathing), which could apply to 
any PM woman globally, but the availability, access (especially at night), affordability and quality of WASH infrastructure may be different. These practices were explored further in a Ghanaian WASH infrastructure context in La and Kotei.

\section{Data collection phase two: Ghana}

\section{Methodologies need to be reflexive}

The second phase of data collection, in Ghana, used $\mathrm{OH}$ interviews, participatory photography and participatory mapping [AQıo]. PM and menstruation are taboo within patriarchal Ghanaian society. An exploratory, inductive approach which enables reflexivity was adopted. Exploratory research is a systematic and broad ranging approach to data collection, aiming to maximise the ability to understand social life. Methods should be flexible and open minded to search for data. The data is used to situate the focus of the study using the observations made and integrating the data into grounded theory (Stebbins, 2008). Adaptations to the methodologies used are needed according to Ghanaian taboos and beliefs about the menopause, to unveil hidden knowledge. Methodologies are unstructured and responsive to the context, particularly where taboos (e.g. menstruation) are concerned.

\section{Peeling back the onion skin: making the private public}

Effective participative methods are needed to 'peel back' the onion skin and reveal hidden knowledge. Previously in the UK, 'mass observation' was set up to explore the everyday behaviour of people by recording their experiences of leisure, through questionnaires, secondary data searches and content analysis (Seaton, I997). Similarly, this research used a feminist approach, with three techniques to make private, hidden knowledge of WASH needs for PM women, public knowledge to researchers. Concurrent $\mathrm{OH}$ interviews enable women to tell their stories, PhotoVoice [AQII] depicts these needs, and participatory mapping spatially represents WASH issues. These methodologies triangulate women's voices with data about the environment in which their experiences occur, to paint a wider picture of their realities, which is hidden knowledge.

- $O H$ interviews with women in Kotei and La provided insight into PM WASH practices. Similarly to the phenomenological review interviews, women discussed similar experiences. The interviews in Ghana were the main data collection process; whereas the UK interviews, for the phenomenological review, set the research objectives for Ghana. Unlike the UK, sanitation and water supply services were lacking or of poor quality and not fit for purpose. Women experiencing menorrhagia described concern about a lack of water in shared community toilets, to wash blood away from latrine slabs that easily stain. Disposal of 'secret waste' (heavily stained menstrual hygiene materials such as pads and 
cloths) was a concern and embarrassment due to a lack of secure incinerators. Affordability of public facility charges was problematic for urinary incontinence sufferers. Enabling these women to narrate their experiences provides novel insight into and focuses the researcher towards wide-ranging hidden issues of importance to PM women. Interview transcripts provide a written record of that which is not recorded in literature, producing a physical document of hidden knowledge for analysis.

- Participatory photography, (PhotoVoice), was used to visually record hidden issues faced during the perimenopause. PhotoVoice enables marginalised individuals to raise awareness of the issues that affect them (Blackman and Fairey, 20I4; Chambers, 1997). Three women in Kotei and two in La participated in a PhotoVoice exercise over three days, using digital cameras to photograph their WASH needs. Photographs captured physical infrastructure-related issues, rather than invisible social issues. Images represented the women undertaking daily WASH practices. PhotoVoice showed issues with joint pain for all participants. Issues relating to joint pain arose from all of the methodologies employed, but were easiest to illustrate through photographs, e.g. cleaning the home, carrying and disposing of water, and squatting on pit latrines. Accessing community latrines at a distance was tiring. PhotoVoice enabled women to show issues faced in private spaces such as latrines,

- Participatory mapping 'enables community members to draw their community and highlight places, boundaries, people, infrastructure, or resources of importance' (Skovdal and Cornish, 20I5, II7). For conveying non-physical PM WASH, maps help to illustrate historical, social and cultural information (IFAD, 2009). Participatory mapping was used with two groups of women per community to examine hidden knowledge about water supply and shared sanitation facilities for PM women. Using pre-printed Google satellite images, women identified overlooked WASH needs such as the absence of adequate drainage. Women experiencing menorrhagia said that bath water could be mixed with blood, turning a deep red colour. A lack of drainage for sullage led women to dispose of their wastewater onto the streets or into open stormwater drains, making it visible to others. Wastewater disposal was difficult due to joint pain, and embarrassing. Women needed household waste collection services to avoid solid waste disposal in community dump sites, joint pains in carrying waste, and to conceal heavily soiled sanitary materials. Participatory mapping highlighted issues of distance; water points and toilets were too far to walk to. Participatory mapping facilitated analysis of WASH needs in the context of the local environment. 


\section{Limitations to methods for unveiling hidden knowledge}

Using a phenomenological review to enable PM women to set the research agenda raised methodological challenges. The research began with many unknowns and therefore the interview topic guide lacked detail. Unstructured interviews may have neglected some hidden issues if discussions focused on certain topics more than others. A phenomenological review widened the research focus. PM WASH needs were not only new knowledge, but also wide-ranging and diverse. Assessing which topics warranted greater attention was therefore challenging. A phenomenological review was more time consuming than a narrative review, due to practical elements of organising and conducting interviews and thematic data analysis.

$\mathrm{OH}$ interviews in Ghana were time consuming. Women became tired and lost focus if interviews became lengthy, due to the breadth of topics discussed. Household duties were interrupted over longer periods due to interviews being held in the morning when duties were carried out. PhotoVoice had limitations. Certain hidden WASH needs, such as MHM, may not have arisen when photographs were taken if women were not menstruating. Women may not have wished to take pictures of taboo MHM issues and were not captured. Training and building confidence in women to use the camera is time consuming. Women who were less confident in using the camera asked other people to take photographs for them, which may have restricted photographs taken if there were issues which women wanted to keep between themselves and the researcher. Having only one camera, training time needed between exercises, and the three-day exercise duration restricted the sample to five participants.

The mapping process had limitations. A topic guide for discussions, used to save time and prevent tiredness for women, restricted the opportunities for women to raise their own issues and certain things may have been overlooked. The most hidden and private topics (e.g. MHM) are challenging to discuss, despite their spatial importance. Taboos around menstruation prevented a group of Twi women in Kotei from discussing MHM. Group discussions raises issues if women sympathised with each other.

\section{Analysing hidden knowledge}

Unveiling hidden knowledge required effective data analysis. All of the knowledge gathered was new knowledge and there were no analytical frameworks to guide the analysis process. A thematic analysis where themes were identified through sorting and coding the data with an inductive approach was required. The data from the phenomenological review were coded manually, and the data from Ghana was coded with NVivo, a qualitative data analysis software. Wide-ranging WASH needs of PM women meant that the data was diverse, reflected in a high volume of themes gener- 
ated. Diversity of experiences was also reflective of why the WASH needs of PM women are hidden, because they are experienced by each individual woman, and can vary from woman to woman.

\section{Hidden knowledge unveiled: the WASH needs of PM women}

The methods used in this research were effective in finding hidden knowledge. A combination of the phenomenological review, and the interviews, PhotoVoice and participatory mapping identified various WASH needs for PM women which are otherwise hidden from others. Irregular symptoms during the perimenopause mean that women have increased needs for bathing and laundry, effective MHM, management of urinary incontinence, solid waste management and drinking, to collectively deal with their symptoms. However, the differences in provision of WASH infrastructure in Ghana and the UK, and local cultural taboos, mean that the experiences of meeting WASH needs during the perimenopause differs. The interviews, participatory mapping and PhotoVoice identified additional factors to consider for PM women in low-income countries. A lack of water and solid waste services made MHM challenging for women with heavy and irregular menstruation. Access to toilets is a challenge for PM women with urinary incontinence and heavy menstruation as facilities are generally lacking. Using shared community water and sanitation facilities becomes difficult due to ageing-related joint pain during the perimenopause. Women need to drink more water to deal with symptoms such as hot flushes and night sweats, but this is challenging due to inadequate access to drinking water through a lack of infrastructure and unaffordability. The data from Ghana reveal that the availability and design of WASH services in a local context significantly influenced PM women's ability to meet their hygiene needs. Adapted participative methods as demonstrated in this article were needed to find this data, which is hidden knowledge.

\section{Discussion: exploring hidden knowledge}

This article has discussed the concept of hidden knowledge and using the example of WASH needs for PM women, demonstrates how this can be addressed. Hidden knowledge of an issue does not mean it should not or cannot be researched, but rather that an appropriate environment and effective methodology is needed. The adoption of SDG6, for available and sustainable management of water and sanitation for all (UN, 20i6[AQ3]), encourages researchers to enable those with hidden WASH needs to share them to have them met. Finding hidden WASH knowledge uses methodologies aligning with Principle Two of the Dublin Statement on Water and Sustainable Development (UN, I992[AQI2]), to ensure that 'water development and management should be based on a participatory approach, involving users, planners and policy 
makers at all levels'. Participatory approaches enable the realities of excluded individuals who often cannot voice their experiences to be heard (Chambers, I997). Yet, excluded issues, as well as excluded groups, require inclusion on research agendas.

Unveiling hidden knowledge through participative approaches for equitable WASH provision illustrates how salient knowledge needs to be addressed. Intersectionality discourses focusing on its complexity and the fluidity of identity alone, veils how spatial orderings ignore how specific hidden groups and hidden issues are excluded (Valentine, 2007[AQ4]). Landscapes of 'power' (Lefebvre, I99I[AQ4]) and spaces of exclusion (Sibley, I995[A24]) are characterised by unjust institutional practices, creating hegemonic structures which exclude groups (Valentine, 2007) and hidden knowledge of issues experienced within them that are not shared. Katz (I996[AQ4]) critiques Harvey (I975) for failing to recognise the intersections between gender inequality and class in urban areas, oppressing urban women. Finding hidden knowledge provides a path to transcend these structures and practices of exclusion of social groups and move towards inclusion through addressing issues within and across these groups that remain concealed. The example of PM WASH needs shows how effective methods to reveal hidden knowledge can have practical impacts on planning, design and development of infrastructure and space, to address hidden but significant issues for different people.

Hidden knowledge intertwines with intersectionality of different aspects of identity. Methods to find hidden knowledge concealed by intersections require adaptation according to the research context. Researching PM WASH needs highlights how knowledge can be hidden from others due to local taboos. Reluctance by women to discuss menstruation means that girls grow up knowing very little about it until they menstruate (House et al., 20I4[AQ4]). Processes of unveiling hidden knowledge therefore need to consider why such knowledge is hidden, and be able to unveil it with sensitivity.

\section{Conclusion}

The task of researching PM WASH needs has highlighted how finding hidden knowledge involves going beyond literature and theoretical frameworks, and towards more practical participative research. While we cannot avoid theory (Hubbard et al., 2002[AQ4]) (e.g. the Johari Window, tacit knowledge) practical elements of research are needed to unveil hidden knowledge. Feminist research can engage with existing practical lessons from fields such as civil engineering and development studies (Chambers, I997), when theory alone is not sufficient to find hidden knowledge. Feminist discourse enables hidden knowledge to be revealed when used with practical approaches. Analysing and engaging with empirics as well as theoretical discourses, unveils hidden knowledge, as the realities of those experiencing previously under- 
researched issues which impact on those without power, but are ignored in powerladen landscapes (Valentine, 2007) become more vivid. For wider policy agendas, such as the SDGs, this approach has potential value in contributing to their achievement through methods which place those who do not have a voice and are last (Chambers, I997) at the centre of research.

\section{References}

Akhlaque, U., Ayaz, S., Akhtar, N. and Ahmad, N. (2017) 'Association of bone mineral density and body mass index in a cohort of Pakistanis: relation to gender, menopause and ethnicity', The Egyptian Rheumatologist, 39(I), 39-43.

Avis, N. E., Colvin, A., Bromberger, J. T., Hess, R., Matthews, K. A., Ory, M. and Schocken, M. (2009) 'Change in health-related quality of life over the menopausal transition in a multiethnic cohort of middle-aged women: study of women's health across the nation', Menopause, i6(5), 860-69.

Bairy L., Adiga, S., Bhat, P. and Bhat, R. (2009) 'Prevalence of menopausal symptoms and quality of life after menopause in women from South India', Australia and New Zealand Fournal of Obstetrics and Gynaecology, 49(I), ro6-og. [AQ13]

Becker, C. (I992) Living and relating: an introduction to phenomenology, Newbury Park, Sage. [AQI3] Bhakta, A., Annan, G., Esseku, Y., Esseku, H., Fisher, J., Lartey, B. and Reed, B. J. (2016) 'Finding hidden knowledge in WASH: effective methods for exploring the needs of perimenopausal women in Ghana', Paper presented to the 39th Water, Engineering and Development Centre International Conference, Kumasi, I I-I5 July.

Bhakta, A., Fisher, J. and Reed, B. J. (20I4) 'WASH for the perimenopause in low-income countries: changing women, concealed knowledge?', Paper presented at the $37^{\text {th }}$ Water, Engineering and Development Centre International Conference, Hanoi, I5-I9 September.

Binh, T. and Nhung, B. (2016) 'Prevalence and risk factors of type 2 diabetes in middle-aged women in Northern Vietnam', International Journal of Diabetes in Developing Countries, 36(2), I50-57.

Blackman, A. and Fairey. T. (2014) The Photovoice manual: a guide to designing and running participatory photography projects, https://photovoice.org/wp-content/uploads/2014/og/PV_Manual. pdf, accessed i6 November 2016.

Briggs, P. and Kovac, G. (2015) 'Clinical features of the menopausal transition', in N. Paney, P. Briggs and G. Kovac (eds) Managing the menopause: 2Ist century solutions, Cambridge, Cambridge University Press, 29-35.

Brisolara, S. (2014) 'Feminist theory: its domains and applications', in S. Brisolara, D. Seigart and S. SenGupta (eds) Feminist evaluation and research: theory and practice, New York, Guilford Press, 3-4I.

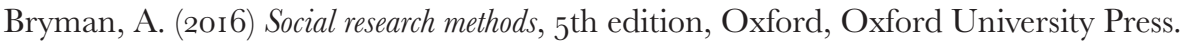

Carastathis, A. (20I4) 'Reinvigorating intersectionality as a provisional concept', in N. Goswami, M. O'Donovan, and L. Yount (eds) Why race and gender still matter: an intersectional approach, London, Pickering and Chatto, 59-70. 
Castelo-Branco, C., Palacios, S., Mostajo, D., Tobar, C. and Von Helde, S. (2005) 'Menopausal transition in Movima women, a Bolivian native-American', Maturitas, 5I(4), 380-85.

Chambers, R. (I997) Whose reality counts? Putting the first last, London, Intermediate Technology Publications.

Chambers, R. (2006) 'Participatory mapping and geographic information systems: whose map? Who is empowered and who disempowered? Who gains and who loses?' Electronic Journal on Information Systems in Developing Countries, 25(2), I-I I. [AQI3]

Chompootweep, S., M. Tankeyoon, K. Yamarat, P. Poomsuwan and N. Dusitsin (I993) 'The menopausal age and climacteric complaints in Thai women in Bangkok', Maturitas, I7(I), 63-7I.

Cotterill, P. (I992) 'Interviewing women: issues of friendship, vulnerability, and power', Women's Studies International Forum, I5(5-6), 593-6o6. [AQ 13 ]

Crenshaw, K. W. (I997) 'Beyond racism and misogyny: black feminism and 2 live crew', in C. Cohen, K. Jones and J. Tronto (eds) Women transforming politics: an alternative reader, New York, New York University Press, 549-68.

Crofts, T. and Fisher, J. (2012) 'Menstrual hygiene in Ugandan schools: an investigation of low-cost sanitary pads', Fournal of Water, Sanitation and Hygiene for Development, 2(I), 50-58.

Da Silva, A. R. and D'andretta Tanaka, A. C. (2013) 'Factors associated with menopausal symptom severity in middle-aged Brazilian women from the Brazilian Western Amazon', Maturitas, 76(I), 64-69.

Deleyser, D. and Shaw, W. (2013) 'For menopause geographies', Area, 45(4), 504-06.

DFID (Department for International Development) (2003) Tools for development. A handbook for those engaged in development activity, London, DFID.

Dill, B. T. and Zambrana, R. E. (2009) 'Critical thinking about inequality: an emerging lens', in B. T. Dill and R. E. Zambrana (eds) Emerging intersections: race, class, and gender in theory, policy and practice, New Brunswick, New Jersey: Rutgers University Press, I-2 I.

Duckitt, K. (20I0) 'Managing perimenopausal menorrhagia', Maturitas, 66(3), 25 $5^{-} 5^{6}$.

Ellard-Gray, A., Jeffrey, N. K. Choubak, M. and Crann S. E. (2015) 'Finding the hidden participant: solutions for recruiting hidden, hard-to-reach, and vulnerable populations', International Fournal of Qualitative Methods, I4(5), I-IO.

Elliot, E., Watson, A. J. and Harries, U. (2002) 'Harnessing expertise: involving peer interviewers in qualitative research with hard-to-reach populations', Health Expectations, 5(2), I $72-78$.

Faugier, J. and Sargeant, M. (1997) 'Sampling hard to reach populations', Fournal of Advanced Nursing, 26(4), 790-97.

Gadalla, F. (I986) 'Social, cultural and biological factors associated with menopause', Egyptian Journal of Community Medicine, 2, 49-62.

Ghana Statistical Service (2014) Population and housing census: district analytical report- La DadeKotopon Municipal Assembly, http://www.statsghana.gov.gh/docfiles/2010_District_Report/ Greater\%20Accra/LA\%2oDADEkotopon.pdf (accessed I5 November 20i6).

Gohar, I. E. M. (2005) 'Design, implementation and evaluation of a reproductive health informational guide for postmenopausal women', Unpublished thesis (MD), [AQI4] Alexandria University. 
Gosling, L. (2010) Equity and inclusion: a rights-based approach, London, WaterAid.

Graham, H. (1984), 'Surveying through stories', in C. Bell and H. Roberts (eds) Social researching: politics, problems, practice, London, Routledge and Kegan Paul, I04-24. [AQI3]

Greer, G. (I99I) The change: women, aging and the menopause, London, Hamish Hamilton.

Grosz, E. (I987) 'Feminist theory and the challenge to knowledges', Women's Studies International Forum, iо(5), 475-80.

Hamid, T., Pakgohar, M., Ibrahim, R. and Dastjerdi, M. (2015) "Stain in life": the meaning of urinary incontinence in the context of Muslim postmenopausal women through hermeneutic phenomenology', Archives of Gerontology and Geriatrics, 6o(3), 5I4-21.

Hammam, R. A. M., Abbas, R. A. and Hunter, M. S. (2012) 'Menopause and work: the experience of middle-aged female teaching staff in an Egyptian governmental faculty of medicine', Maturitas, 7I(3), 294-300.

Harding, S. (1986) The science question in feminism, Ithaca, Cornell University Press.

Harding, S. (1987) Feminism and methodology: social science issues, Bloomington, Indiana University Press.

Harlow, S. D., Cain, K., Crawford, S., Dennerstein, L., Little, R., Mitchell, E. S., Nan, B., Randolph Jr, J. F., Taffe, J. and Yosef, M (2006) 'Evaluation of four proposed bleeding criteria for the onset of late menopausal transition', fournal of Clinical Endocrinology $\mathbb{E}^{2}$ Metabolism, 9I (9), 3432-38.

Harvey, D. (1975) 'The geography of capital accumulation: a reconstruction of Marxian theory', Antipode, 7(2), 9-2I.

hooks, b. (1984) Feminist theory: from margin to center, Boston, South End.

IFAD (International Fund for Agricultural Development) (2009) Good practices in participatory mapping, Rome, IFAD.

Imrie, Rand Edwards, C. (2007) 'The geographies of disability: reflections on the development of a sub-discipline', Geography Compass, I(3), 623-40.

Jewitt, S., and Ryley, H. (20I4) 'It's a girl thing: menstruation, school attendance, spatial mobility and wider gender inequalities in Kenya', Geoforum, 56, I37-47.

Kupoluyi, J. A., Ekudayo, O. O. and Akinyemi, A. I. (2015) 'Nigerian menopause rating scale (MRS): experience in postmenopausal women', Maturitas, 8I(I), I77.

Kwawukume E. Y., Ghosh T. S. and Wilson J. B. (1993) 'Menopausal age of Ghanaian women', International fournal of Gynaecology and Obstetrics, $4 \mathrm{O}(2), \mathrm{I}^{2} \mathrm{I}^{-} 55$.

Leathes, B. (2012) Topic brief: delegated management of water and sanitation services in urban areas: experiences from Kumasi, Ghana, WSUP, http://www.wsup.com/resource/delegated-management-of-water-and-sanitation-services-in-urban-areas-experiences-from-kumasi-ghana/ (accessed I5 November 20I6).

Liu, M., Wang, Y., Li, X., Liu, P., Yao, C., Ding, Y., Zhu, S., Bai, W. and Liu, J. (2013) 'A health survey of Beijing middle-aged registered nurses during menopause', Maturitas, 74(I), 84-88.

Loue, S. and Sajatovic, M. (2008) Encyclopaedia of ageing and health, New York, Springer Science and Business Media.

Luft, J. (I96I) 'The Johari window: a graphic model of awareness in interpersonal relations', Human Relations Training News, 5(9), 6-7. [AQ 15$]$

McCall, L. (2005) 'The complexity of intersectionality', Signs, 30(3), I77I-80o. 
McLean, A. and Flynn, C. (2013) "'It's not just a pap-smear": women speak of their experiences of hospital treatment after miscarriage', Qualitative Social Work, I2(6), 782-98. [AQI3]

McMorrin, F. (2016) WASH advocacy and the global goals for sustainable development, London, WaterAid. [AQI3]

Moore, B. (I98I) 'Climacteric symptoms in an African community', Maturitas, 3(I), 25-29.

Nachtigall, L. E. (1998) 'The symptoms of perimenopause', Clinical Obstetrics and Gynaecology, $4 \mathrm{I}(4), 92 \mathrm{I}-27$.

O’Neill, M. (I996) 'Researching prostitution and violence: feminist praxis', in M. Hester, L. Kelly and J. Radford (eds), Women, violence and male power, Buckingham, Open University Press, $\mathrm{I}^{3} \mathrm{-}-47$.

Oakley, A. (I98I) 'Interviewing women: a contradiction in terms', in H. Roberts (ed.) Doing feminist research, London, Routledge, 30-6I.

Odiari. E. A. and Chambers, A. N. (2012) 'Perceptions, attitudes, and self-management of natural menopausal symptoms in Ghanaian women', Health Care for Women International, $33(6), 560-74$.

Okonofua, F. E., Lawal, A. and Bamgbose,J. K. (I990) 'Features of menopause and menopausal age in Nigerian women', International Journal of Gynecology and Obstetrics, 3I(4), 34I-45.

Polanyi, M. (1958) Personal knowledge, Chicago, University of Chicago Press. [AQI3]

Portelli, A. (I998) 'What makes oral history different?' in R. Perks and A. Thomson (ed.) The oral history reader, New York, Routledge, 63-74.

Prior, J C. (2005) 'Clearing confusion about perimenopause', British Columbia Medical Journal, 47 (Io), $538-42$.

Punyahotra, S, Dennerstein, L. and Lehert. P. (I997) 'Menopausal experiences of Thai women. Part I: symptoms and their correlates', Maturitas, 26(I), I-7,

Randolph, J. J. (2009) 'A guide to writing the dissertation literature review', Practical Assessment, Research and Evaluation, I4(13), I-I3.

Raymond, M. (1993) Doing research on sensitive topics, London, Sage. [AQ13]

Sampselle, C. M., Harlow, S. D., Skurnick, J., Brubaker L. and Bondarenko, I. (2002) 'Urinary incontinence predictors and life impact in ethnically diverse perimenopausal women', Obstetrics and Gynaecology, $100(6), \mathrm{I}_{2} 30^{-} 3^{8}$.

Sangster, J. (I994) 'Telling our stories: feminist debates and the use of oral history', Women's History Review, 3, 5-28.

Seaton, A. V. (1997) 'Unobtrusive observational measures as a qualitative extension of visitor surveys at festivals and events: mass observation revisited', fournal of Travel Research, 35(4), 25-30.

Seffah, J., Kwame-Aryee. R. A., Adanu, R. M. K., Munumi, K. and Awotwi, E. K. (2008) 'Indications for gynecologic surgery and their implications for sexual function in menopausal women', International Journal of Gynaecology and Obstetrics, I03(3), 203-06.

Serteglo, J., Keddey, R. S., Agbemafle, I., Kumordzie S. and Steiner-Aseidu, M. (2012) 'Determinants of menopausal symptoms among Ghanaian women', Current Research fournal of Biological Sciences, 4(4), 507-12. [AQ13]

Sheehy, G. (I99I) The silent passage: menopause, London, Harper Collins.

Shopes, L. (2003) 'Commentary: sharing authority', The Oral History Review, 30(I), I03-IO. 
Singer, M. (2013) 'Studying hidden and hard-to-reach populations', in J. Schensul and M. D. LeCompte (eds) Specialized ethnographic methods: a mixed methods approach, London, Lanham, Rowman and Littlefield, 255-317.

Skovdal, M. and Cornish, F. (2015) Qualitative research for development: a guide for practitioners, Bourton on Dunsmore, Practical Action Publishing.

Stanley, L. and Wise S. (1983) Breaking out: feminist consciousness and feminist research, London, Routledge and Kegan Paul. [AQI3]

Stearns, V., Ullmer, L., Lopez, J. F., Smith, Y., Issacs, C. and Hayes D. F. (2002) 'Hot flushes', Lancet, 360(9348), I85I-6I.

Stebbins, R. A. (2008) 'Exploratory research', in L. Given (ed.) The Sage encyclopaedia of qualitative research methods, Los Angeles, Sage, 327-28.

Trivedi, R. and Pandya, M. (2017) 'A survey study of menopausal syndrome in western Gujarat region', International Journal of Scientific Research and Engineering, 5(7), 6692-97.

UN (United Nations) (2016) UNDP support to the implementation of sustainable development goal 6: sustainable management of water and sanitation, New York, United Nations.

UNICEF (United Nations Children's Fund) and WHO (World Health Organisation) (2015) 'Progress on sanitation and drinking water 2015 update and MDG assessment', Geneva, UNICEF and WHO.

Wambua, L.T. (I997) 'African perceptions and myths about menopause', East African Medical Journal, 74(Io), 645-46.

Wasti, S., Robinson, S. C., Akhtar, Y., Khan, S. and Badaruddin. N. (r993) 'Characteristics of menopause in three socioeconomic urban groups in Karachi, Pakistan', Maturitas, I6(I), $6 \mathrm{I}-69$.

Woodfield, J. (I997) 'Gendered experience of skilled manual labour in Derby's industries: I939-6o', PhD thesis, Derby, University of Derby.

Wylie, A. (2003) 'Why standpoint matters', in R. Figueroa and S. Harding (eds) Science and other cultures: issues in philosophies of science and technology, New York, Routledge, 26-48. 